\title{
LA IDEA DE PERSONA Y DIGNIDAD HUMANA*
}

\author{
THE IDEA OF PERSON AND HUMAN DIGNITY
}

\author{
Reynaldo Bustamante Alarcón**
}

\begin{abstract}
RESUMEN: Partiendo de distintas racionalidades parciales que, en diferentes pasajes de la historia, han aportado a la idea de persona y dignidad humana, en este artículo se profundiza en lo que significa ser persona, en el sentido de la dignidad que le es propia. Se reflexiona así sobre el puesto que le corresponde en una sociedad justa, a la altura de nuestro tiempo, con las consecuencias que se derivan de ello, particularmente para la moral, la política y el Derecho. Un cierto tipo de sociedad donde cada persona pueda encontrar las condiciones adecuadas para el desarrollo de todas las dimensiones de su humanidad y vivir de manera armoniosa en comunidad y con el resto de la naturaleza. Estamos ante una reflexión que busca contribuir a que el ser humano pueda desarrollarse plenamente, con su esfuerzo, pero con el apoyo de los demás. Un modo de convivencia social donde la democracia y el Estado de Derecho se presentan, junto con los derechos fundamentales, como las formas de organización jurídico-políticas más acordes con la dignidad humana, con los objetivos de racionalización y humanización que se persiguen para construir y fortalecer una sociedad justa.
\end{abstract}

ABSTRACT: Starting from different partial rationales that, in different passages of history, have contributed to the idea of person and human dignity, this article delves into what it means to be a person, in the sense of the dignity that is its own. Thus, we reflect on the position that corresponds to it in a just society, at the height of our time, with the consequences that derive from it, particularly for morals, politics and the Law. A certain type of society where each person can find the appropriate conditions for the development of all dimensions of their humanity and live harmoniously in community and with the rest of nature. We are facing a reflection that seeks to contribute to the human being able to develop fully, with his effort, but with the support of others. A mode of social coexistence where democracy and the rule of law are presented, along with fundamental rights, as the forms of legal-political organization most in line with human dignity, with the objectives of rationalization and humanization that are pursued to build and strengthen a just society.

PALABRAS CLAVE: persona, dignidad, ser humano, moral, política, Derecho.

KEYWORDS: person, dignity, human being, moral, politics, law.

Fecha de recepción: 06/04/2020
Fecha de aceptación: 06/04/2020

doi: https://doi.org/10.20318/universitas.2020.5518

* Trabajo presentado en el I Congreso de Alumnos y Alumnas del IDHBC. Artículo
basado en el libro de mi autoría, y de igual nombre, publicado por la editorial
Dykinson y el IDHBC, 2018 .
** Doctor por la Universidad Carlos III de Madrid. Profesor del Departamento de
Derecho de la Universidad del Pacífico, Perú. E-mail: rbustamante@isdeh.org 


\section{1.- EL SIGNIFICADO DE SER PERSONA Y EL SENTIDO DE LA DIGNIDAD HUMANA}

El reconocimiento generalizado que ha alcanzado la idea de que «todo ser humano es persona» y que «toda persona tiene dignidad» es una conquista histórica: un gran esfuerzo de racionalización propio de las sociedades occidentales, aunque sin limitarse a ellasque se ha gestado progresivamente, durante siglos, con múltiples luchas y aportes culturales ${ }^{1}$. En esa sencilla pero profunda expresión radica el sentido de nuestra cultura, la manera como hemos decidido vivir en sociedad y realizar nuestros planes de vida. Si esa expresión cambiara, nuestros modos de vida y la organización de la sociedad serían completamente distintos. La historia da buena cuenta de ello.

Al observar la naturaleza humana advertimos que el ser humano es un ser único. Por naturaleza humana nos referimos a lo que somos, a lo que tenemos en nosotros y por nosotros mismos, no solo de manera actual sino también potencial, y que nos distingue de todo lo demás. Implica preguntarnos por la fuente y origen de los estados o movimientos que nos son propios $-y$ no solo por los estados o movimientos propiamente dichos-, lo que hace posible que nos comportemos de la manera que corresponde a lo que somos. Una indagación seguida por muchos desde tiempos antiguos hasta la actualidad $^{2}$. No hay en el Universo conocido otra creatura como el ser humano: los seres humanos tenemos una naturaleza (expresada en capacidades, actuales o potenciales, incluso en posibilidades, para razonar, diseñar un plan de vida, crear cultura, etc.) que los otros seres no tienen, como tampoco las tienen cualquier creación del intelecto humano, por lo menos no en el mismo grado superior.

Pongamos como ejemplo la capacidad de cada ser humano para elegir y autodeterminarse racionalmente, sea de manera actual o potencial, en el plano moral, con independencia de las causas externas que incidan sobre él$^{3}$. Esto lo presenta como un ser que puede plantearse fines: progresivamente puede crear 0 asumir libremente su propio plan de vida, sus propias normas para regir su destino; incluso proponer otras con las cuales organizar la vida comunitaria, alcanzar un orden justo de convivencia, etc. Lo presenta también como un ser que existe como un fin en sí mismo: al tener la capacidad potencial de autodeterminarse racionalmente, el ser humano encuentra su fin, su misión o razón de ser, en sí mismo,

\footnotetext{
1 Un reconocimiento que se sintetiza muy bien con aquella frase de Séneca: Homo homini sacra res: «El hombre es cosa sagrada para el hombre» (Cartas morales a Lucilio, Biblioteca Clásica, introducción, traducción y notas de Ismael Roca Melía, Gredos, Madrid, 1986, dos volúmenes, p. 133).

2 Cfr. ARISTóteles. Metafísica, Libro Quinto, IV, traducción de Patricio Azcárate, Obras de Aristóteles, Madrid, 1875, tomo 10.

3 Cfr.: KANT, Immanuel. Fundamentación para una metafísica de las costumbres (1785), Humanidades, traducción y estudio preliminar de Roberto R. Aramayo, Alianza Editorial, Madrid, 2002, pp. 125 y 131.
} 
orientándose hacia su propia realización, hacia el desarrollo integral de todas las dimensiones de su ser (sin perjuicio de buscar contribuir al desarrollo de los demás y cuidar de la naturaleza, pues prontamente descubre también que el pleno desarrollo no puede alcanzarse en solitario). La razón de la existencia del individuo humano, de cada ser humano, no es entonces la de servir de medio para la realización de otros fines. Cada uno de nosotros somos un fin en sí mismo. Los animales y el resto de la naturaleza no poseen esa cualidad: no tienen la capacidad potencial de plantearse fines ni son fines en sí mismos; menos aún las obras del ingenio humano.

Al tener todos los seres humanos la misma naturaleza, y ser esta de una envergadura que hace del ser humano un ser único, esta constatación racional justifica que se reconozca a cada ser humano un estatus especial y un tratamiento preferente frente a todo lo demás. Justifica que se reconozca que todo ser humano es persona y que toda persona tiene dignidad ${ }^{4}$.

Persona y dignidad se presentan así como «dos caras de una misma moneda», dos formas de referirse al ser humano, expresar las dimensiones que lo caracterizan y exigir un tratamiento acorde con su naturaleza. Si bien se trata de dos categorías que se encuentran interrelacionadas, en estricto no se superponen. La dignidad eleva a la persona a una posición eminente, y la persona otorga a la dignidad su verdadero contenido. Decir que el ser humano tiene un mayor valor (dignidad) requiere que se profundice en todas las dimensiones de su ser (persona) para que las conclusiones y exigencias que se deriven racionalmente guarden coherencia con su naturaleza. Por ese motivo, la idea que se tenga sobre la persona influye en la noción que se exprese sobre su dignidad, y viceversa. Muchas veces esta distinción pasa desapercibida, pero si no se las aborda adecuadamente, y de manera conjunta, nuestra imagen sobre la condición humana podría resultar distorsionada.

\section{1.- Las perspectivas descriptiva y prescriptiva sobre la persona}

Hablar de persona humana, o simplemente de persona para referirse al ser humano, añade algo a «persona» pero también a «humano». La palabra persona se contrapone a la de animal o cosa y se vincula con la de individuo, pero, en estricto, no se identifica con él: la individualidad alude a una realidad existente en sí misma, distinta a las demás realidades, por lo que, si bien toda persona es un individuo, no todo individuo es persona (dependiendo del género al que pertenezca puede hablarse de individuo humano, individuo

\footnotetext{
${ }^{4} \mathrm{Si}$ existieran en el Universo otros seres que, a pesar de no pertenecer a nuestra especie, tuviesen una naturaleza que justificase que se les reconozca como personas, es decir, como seres dignos; correspondería otorgarles ese reconocimiento.
} 
animal, etc.). Se aproxima al término ser humano, pero estrictamente tampoco se le superpone; no solo porque la palabra persona es usada para designar también otras entidades (como las personas divinas en el ámbito religioso), sino porque lo califica de manera especial cuando se refiere a él. Mientras el término ser humano linda con el mundo de la naturaleza, de la pura existencia, y el vocablo individuo resalta su singularidad, su individualidad frente a cualquier otra entidad, la palabra persona destaca además su dignidad y lo relaciona con un proyecto de realización integral, con un conjunto de valores éticos, políticos, y jurídicos y, por tanto, con la civilización y la cultura. El ser humano recibe una determinación importante cuando se le considera persona (porque se le asocia con un valor eminente, con un proyecto que lo ubica como titular de una serie de derechos y deberes que deben ser atendidos para su plena realización); y la persona recibe una significación no menos importante cuando se le considera humana (porque se le asocia con los diversos aspectos y circunstancias de esa condición).

Profundizar en lo que significa ser persona requiere tener en cuenta dos presupuestos que surgen de su relación con la naturaleza humana. En primer lugar, como el concepto de persona identifica a todo ser humano, el significado de persona tiene que comprender todo lo que el ser humano es, todo lo que caracteriza su naturaleza. No podría incluirse dentro del concepto de persona algún extremo que afecte o contradiga la naturaleza humana. En segundo lugar, como el concepto de persona denota el estatus especial, el tratamiento preferente que se reconoce a favor de los individuos humanos frente a todo lo demás, el significado de persona debe expresar ese calificativo especial, la vinculación del ser humano con un valor eminente, con un proyecto de realización integral.

Para asegurar ese propósito haremos uso de dos perspectivas. Una descriptiva para comprender en la definición de persona todo lo que el ser humano es, según su naturaleza; y una prescriptiva para postular lo que el ser humano está llamado a ser por su naturaleza 5 . Dos perspectivas sobre la condición humana que se encuentran comunicadas entre sí, sin que una prescinda de la otra. Solo se las distingue a efectos metodológicos para expresar mejor lo que significa ser persona.

\footnotetext{
${ }^{5}$ Es un sentido similar, no igual, al otorgado por Carlos Santiago Nino cuando se ocupa de distinguir los tipos de discursos. Se dice que un discurso puede ser: descriptivo, prescriptivo o mixto. El discurso descriptivo se ocupa de lo que es algo en la realidad, de explicar, designar o utilizar situaciones de hecho sin formular propuestas o valoraciones normativas. El discurso prescriptivo no describe lo que es, sino que postula lo que debería ser; lo que sostiene puede no existir en la realidad, pero es muy útil para procurar su transformación. El discurso es mixto cuando resulta de una combinación de ambos, con el acento puesto en un tipo u otro, de ser el caso. Lo usual es que los discursos sean mixtos, aunque con una marcada tendencia a ser descriptivos o prescriptivos, según sea el caso (cfr. del mencionado autor: Derecho, moral y política. Una revisión de la teoría general del derecho, Ariel Derecho, Ariel, Barcelona, 1994, pp. 41-42).
} 
Desde un punto de vista descriptivo, al decir que el ser humano es persona estamos expresando todo lo que es o, mejor, quien es. La palabra persona comprende todas las dimensiones del ser humano (su corporeidad, racionalidad, libertad, sociabilidad, espiritualidad, entre otras), todo lo que es propio de su naturaleza, cuanto le diferencia de otra existencia natural, creación artificial o transpersonal, fundamenta su valía y existe en un individuo humano concreto. No lo hace de manera reduccionista 0 fragmentada (desvinculando esas dimensiones entre sí, prescindiendo de alguna o subordinando una frente a las demás), sino $-y$ esto es muy importante- integrando todas sus dimensiones en una unidad. Jacques Maritain lo expresa así: «Cuando decimos que un hombre es una persona, queremos decir que no es solamente un trozo de materia, un elemento individual en la naturaleza, como un átomo, una espiga de trigo, una mosca o un elefante son elementos individuales en la naturaleza». El ser humano posee inteligencia y voluntad, «no existe solamente de una manera física. Hay en él una existencia más rica y más elevada, sobreexiste espiritualmente en conocimiento y amor». Es en cierta medida «un todo, y no solamente una parte; es un universo en sí mismo, un microcosmos, en el cual el gran universo íntegro puede ser contenido por el conocimiento, y que por el amor puede darse libremente a seres que son para él como otros "él mismo"». La noción de persona implica así las de totalidad e independencia: «Por indigente y aplastada que esté una persona es, como tal, un todo, y en tanto que persona subsiste de manera independiente. Decir que el hombre es una persona, es decir que en el fondo de su ser es un todo, más que una parte, y más independiente que siervo». $Y$ concluye: «La persona tiene una dignidad absoluta porque está en relación directa con lo absoluto, único medio en que puede hallar su plena realización; su patria espiritual es todo el universo de los bienes que tienen valor absoluto, y que reflejan en cierto modo, un absoluto superior al mundo, hacia el cual tienden» 6 .

Desarrollando esta perspectiva, al decir que el ser humano es persona estamos significando principalmente lo siguiente:

$1^{\circ}$. La condición de persona denota la subsistencia individual del ser humano. En primer lugar, pone de relieve que cada ser humano es un ser corpóreo que existe en sí mismo y por sí mismo en absoluta independencia: tiene una existencia propia, sustancial, al no ser atributo o cualidad de ningún otro ser, al no necesitar de ningún sustrato para poder subsistir con las condiciones propias de su naturaleza. En segundo lugar, destaca que, hasta el final de nuestra existencia, cada uno de nosotros subsistimos como seres humanos, mantenemos nuestra identidad $y$, por tanto, nuestra condición de personas, sin importar los estados que atravesemos en nuestro

\footnotetext{
${ }^{6}$ Los derechos del hombre y la ley natural (1945), traducción de Héctor F. Miri,
} Leviatán, Buenos Aires, 1982, pp. 12-13. 
desarrollo, ni el transcurso del tiempo, las circunstancias o los cambios de diferente tipo que podamos experimentar (los cambios influyen en nuestra personalidad, mas no en nuestra identidad). Hasta el fin de nuestros días seguimos siendo los mismos. En tercer lugar, resalta que cada ser humano es un individuo con capacidades, potencialidades y posibilidades diferenciadas que caracterizan su humanidad. Esto significa que no existe como parte de otra entidad natural ni de alguna creación artificial o transpersonal; por el contrario, existe como un todo, una unidad que es una totalidad completa en sí misma, que preexiste a cualquier colectivo, llámese pueblo, Estado, nación, etc., así como a cualquier obra de su creación. Significa también que cada ser humano posee un modo particular de existencia que lo hace único: singular, inconfundible, insustituible, irrepetible e incomunicable (intransferible), es decir, distinto a todo lo demás, incluso a aquellos que comparten su misma naturaleza. No podemos ser reemplazados por nada ni por nadie.

Decimos que el ser humano es distinto a «todo lo demás» o, si se prefiere, «al resto de la naturaleza», y no que es diferente a «los otros animales» porque no es adecuado calificar al ser humano como un animal más, aunque superior. Esta última idea es propia de posiciones monistas que plantean que entre las especies se da una continuidad, una simple diferencia de grados, por lo que calificar al ser humano como un animal sería coherente con la proximidad que, según ellas, existe entre esas especies. No es, sin embargo, una postura correcta. No solo porque la naturaleza del ser humano y la del animal son diferentes, sino porque las posiciones monistas solo atienden a la esfera biológica del ser humano, dejando de lado otras dimensiones de su humanidad. ¿Puede ser clasificado el ser humano como un animal cuando genera historia y cultura? Nos preguntamos si, en general, no estamos ante el deseo de querer clasificarlo todo, de querer encasillar las distintas realidades en categorías ya existentes. «Sin ser ni dios ni animal, ¿no puede el hombre contentarse con ser hombre y vivir en armonía con los otros seres, tanto humanos como animales?» 7 . Debemos tener cuidado con las palabras, si bien no son suficientes para construir la realidad, muchas veces resultan siendo significativas para hacerlo.

$2^{\circ}$. La calidad de persona hace referencia también a la racionalidad que caracteriza a la naturaleza humana. Racionalidad entendida como la interrelación de nuestras capacidades, actuales o potenciales, para pensar, razonar, elegir, construir la moralidad, socializar, entre otras dimensiones que expresan nuestra humanidad. Sin que signifique omitir la importancia de las demás dimensiones, resalta nuestra sociabilidad, nuestra capacidad generativa para dialogar y buscar la vida comunitaria. Una dimensión que nos permite constatar prontamente, con ayuda de la razón, que nadie puede

7 LE BRAS-CHOPARD, Armelle. El zoo de los filósofos: de la bestialización a la exclusión, traducción de María Cordón, Taurus, Madrid, 2002, p. 342. 
realizarse plenamente en solitario. Necesitamos del otro para lograrlo. Al reconocernos como personas ponemos de relieve nuestra recíproca necesidad de salir al encuentro de los demás, incluyendo el resto de la naturaleza, para buscar el bien común y construir una convivencia armoniosa y vivificadora.

30. Al calificar al ser humano como persona se destaca también que es un fin en sí mismo, que posee una dignidad que merece la mayor consideración y respeto. Lo es porque tiene la capacidad potencial para plantearse fines, para autodeterminarse racionalmente, y en el ejercicio de esa capacidad encuentra su fin, su misión o razón de ser, en sí mismo, orientándose hacia su propia realización, hacia el desarrollo integral de todas las dimensiones de su ser.

40. La calificación de persona indica además que el ser humano es un sujeto moral, político y jurídico que crea normas en esos órdenes y se orienta por ellas. Sin el ser humano no es posible concebir una organización social, ni la moral, la política o el Derecho. Por esa razón ese reconocimiento es un presupuesto epistemológico para reflexionar y operar en esos ámbitos. María Lacalle explica este sentido en cuanto al Derecho se refiere: «En la medida en que el hombre es protagonista de las relaciones jurídicas es también, de suyo, sujeto del Derecho. Por consiguiente, todo ser humano es, por su propia naturaleza, sujeto del Derecho -persona en sentido jurídico-». Desde este punto de vista, «el Derecho positivo propiamente no atribuye, sino reconoce la subjetividad jurídica que todos y cada uno de los seres humanos tienen como propia [...] todo ser humano es titular actual de derechos y obligaciones por el mero hecho de ser hombre»8.

Desde un punto de vista prescriptivo, al decir que el ser humano es persona estamos haciendo referencia a todo lo que está llamado a ser, o puede llegar a ser, a su condición de partícipe y responsable del proyecto de humanización 0 , si se prefiere, de personificación. Es un sentido que destaca la dimensión moral del ser humano, vinculándolo con ideales de autorrealización y de cooperación, sin menoscabar su autonomía, su libertad, pero en un contexto de responsabilidad y solidaridad. Es en cierta medida el sentido que le dan autores como Julián Marías, cuando dice: «Entendemos por persona una realidad que no es solo real. Una persona "dada" dejaría de serlo. El carácter programático, proyectivo, no es algo que meramente acontezca a la persona», sino que la caracteriza. «La persona no "está ahí", nunca puede como tal estar ahí, sino que está viniendo». Para evitar confusiones, precisa: «Cuando decimos que "se está haciendo", podemos fácilmente entenderlo mal; bien en el sentido de que la persona todavía no esté hecha, o bien de que lo buscado sea su "resultado"». Tal interpretación no sería correcta: «la persona es ya, está hecha como

${ }^{8}$ La persona como sujeto de derecho, Dykinson, Madrid, 2013, p. 230. 
persona, y por otra parte no interesa su "acabamiento" o resultado. Su ser actual es estarse haciendo, mejor, estar viniendo». Lo prueba toda relación estrictamente personal, como la amistad y el amor, que la persona mantiene con otras. En ella «el "estar" es un "seguir estando", hecho de duración y primariamente de futuro, un constante estar yendo y viniendo; sobre todo, un "ir a estar". La relación personal, en cuanto es verdaderamente personal y no "cosificada", es siempre "víspera del gozo", aun en la presencia o la posesión más plenas»9.

Desarrollando esta otra perspectiva, al decir que el ser humano es persona estamos significando también lo siguiente:

10. El ser humano, en tanto persona, está llamado a alcanzar, con su esfuerzo -pero con el apoyo de los demás-, su desarrollo integral: el máximo desarrollo posible de todas las dimensiones de su humanidad, todo lo que le sea posible en su vida histórica. En esto consiste parte de la empresa de ser persona: trabajar cotidianamente para perfeccionar la propia vida. El individuo atentaría contra su eminente valor si renuncia a luchar por su propio desarrollo, si se duerme en el sitial que hubiera obtenido o le hubiera correspondido y no se esfuerza en ser plenamente persona en todas las circunstancias concretas de su vida: como hijo, como padre, como esposo, como amigo, como profesional, como ciudadano y gobernante; en fin, en todos los ámbitos de su vida, tanto públicos como privados.

$2^{\circ}$. Considerar al ser humano como persona implica destacar también que es un actor de la vida social, corresponsable del desarrollo de su comunidad, de los demás individuos que como él son personas. Si bien se es persona por el solo hecho de ser humano, se actúa coherentemente con esa condición si, además del compromiso con uno mismo, el ser humano no es indiferente con la suerte del otro, si se compromete con el bienestar de quienes, como él, también son personas. Es una consecuencia ineludible de su sociabilidad: en el encuentro generoso y servicial con el otro, el ser humano no solo contribuye al reconocimiento y bienestar de aquel otro, sino que avanza en su propio desarrollo al responder a sus necesidades más profundas de convivencia, paz, justicia y felicidad. Será la auténtica participación libre de todos los seres humanos en la realización del bien común, la clave para la construcción de una sociedad justa; participación en la construcción de esta sociedad que a su vez contribuirá al desarrollo integral de la persona.

30. La empresa de ser persona exige también volver la mirada a la naturaleza, a su cuidado y protección, e insistir en el disfrute racional de sus recursos, de tal manera que se pueda gozar de un desarrollo sostenible que asegure el bienestar de todas las especies y el disfrute de sus beneficios a las generaciones futuras. El ser humano, en tanto persona, tiene el deber de cuidar la naturaleza a fin

\footnotetext{
9 Antropología metafísica: la estructura empírica de la vida humana, Revista de Occidente, Madrid, 1970, p. 45.
} 
de que su relación con ella, incluyendo su propio desarrollo y el de los demás, sea auténticamente liberadora y vivificadora.

\section{2.- Las exigencias que se derivan de la dignidad humana}

En armonía con lo que significa ser persona, la dignidad es el eminente valor de la persona por el solo hecho de serlo. Remite al sentido especial de su condición, sea cual fuere la circunstancia de la vida social e histórica en la que se encuentre. Ubica a la persona en una posición preferente frente a cualquier otra existencia natural y frente a cualquier creación artificial o transpersonal. Exige para esta un trato acorde con el eminente valor que le corresponde.

La dignidad tiene un carácter inherente a toda persona que refleja la igualdad básica entre todos los hombres y mujeres. Supone el mutuo reconocimiento de esa igual dignidad entre todos y cada uno de nosotros. No podría defenderse la dignidad de uno y negársela a los demás. La tenemos todos, absolutamente todos los seres humanos, independientemente de nuestras capacidades, potencialidades y posibilidades, de las particulares circunstancias que nos toque vivir. Es independiente, además, de que adoptemos o no comportamientos virtuosos, de que nuestro comportamiento sea indigno o de que nuestra propia percepción sea disconforme con el valor de nuestra condición humana. Esto se debe a que la dignidad lo es de la persona y no de sus circunstancias. Por eso la dignidad no desaparece, no se ve mermada, cuando se actúa indignamente; por el contrario, tanto ella como nuestra condición de persona exigen que combatamos los vicios de nuestro comportamiento que minan nuestra humanidad y perjudican a los demás. Lo sintetiza muy bien Jesús González Amuchastegui: «[La dignidad] la tienen todos los seres humanos, igual y esencialmente, con independencia de sus méritos y capacidades, o de cualesquiera otros rasgos contingentes que nos caracterizan»10.

Así considerada, la dignidad cumple una doble función: en primer lugar, como cualidad intrínseca a toda persona, destaca su eminente valor, el trato preferente que le corresponde frente a todo lo demás; en segundo lugar, en armonía con ello y dada su fuerte carga valorativa, actúa como puente axiológico, como término de enlace entre el ser de la persona y el deber ser de los preceptos que se determinen o estipulen racionalmente para favorecer la realización de todas las dimensiones de la persona. En otras palabras, mediando la voluntad racional, la dignidad actúa también como el valor supremo del cual se derivan las normas necesarias o útiles para el pleno desarrollo de la persona.

Una de las manifestaciones de esta doble función de la dignidad es la de servir de principal referente axiológico para fundamentar los

\footnotetext{
10 Autonomía, dignidad y ciudadanía. Una teoría de los derechos humanos, Tirant lo blanch, Valencia, 2004, p. 421.
} 
derechos esenciales de las personas - los llamados derechos humanos o fundamentales-, delimitar su contenido y orientar su ejercicio. En palabras de Francisco Javier Ansuátegui: «[E]s necesario no desatender la necesidad de una poderosa fundamentación moral de los derechos. Y es precisamente en este ámbito en el que el discurso sobre la dignidad humana despliega todo su potencial». Sencillamente, «la dignidad es la referencia axiológica básica de los derechos, la dimensión moral que les da sentido»11.

De conformidad con estas consideraciones, la dignidad puede y debe ser ubicada racionalmente como el prius lógico y ontológico de una sociedad justa, especialmente de la moral, la política y el Derecho (en el sentido de tener una existencia anterior que los condiciona), como su fundamento y fin último, la razón de ser de todos ellos, la que explica e inspira sus fines y a cuyo servicio deben estar siempre orientados. Un valor supremo a partir del cual puede edificarse una moral, con sus exigencias para la política y el Derecho, con miras a alcanzar los objetivos de racionalización y humanización que se persiguen; esto es, para que los diversos niveles de la vida social estén organizados de tal modo que todos los seres humanos pueden alcanzar con su esfuerzo -pero con la ayuda de los demássu desarrollo más pleno. Al llegar a este punto, es posible construir ya un ordenamiento moral, además de político y jurídico, fundado e inspirado en la dignidad de la persona.

Precisamente el rico bagaje conceptual de la idea de persona, asociada al de dignidad (impregnadas ambas por la naturaleza humana, que actúa como fuente de datos, de fundamentos), permite extraer unos materiales normativos para desarrollar toda la virtualidad de la dignidad. Para hacerlo haremos uso de dos perspectivas interrelacionadas. La primera pone atención en la persona; no para prescindir de la comunidad, sino para enfatizar su calidad de sujeto, sus derechos, deberes, etc. La segunda fija su atención en la organización social; no para prescindir de la persona, sino para preguntar cómo debe organizarse la sociedad, y en especial la moral, la política y el Derecho a fin de que se desarrollen todas las dimensiones de nuestra humanidad, es decir, para construir y fortalecer una sociedad justa orientada a nuestro pleno desarrollo (sin dejar de lado la importancia de la comunidad ni el cuidado de la naturaleza). Haciendo uso de estas dos perspectivas, entre las principales exigencias que se derivan racionalmente de la dignidad se encuentran las siguientes:

10. La dignidad implica -como se ha adelantado- que cada uno de nosotros tenemos algo intrínsecamente valioso que no puede entrar en el campo de lo negociable, de lo disponible ni de lo prescindible, sea por parte del poder político, de terceras personas 0

11 "Derechos fundamentales y dignidad humana", en Papeles el tiempo de los derechos, No 10, Año 2011, Instituto de Derechos Humanos Bartolomé de las Casas, Universidad Carlos III de Madrid, pp. 3-4. 
del propio interesado. Indica la existencia en todas y cada una de las personas de un ámbito inviolable que limita el discurso moral, político y jurídico, así como las conductas y decisiones que se adopten en esos órdenes. Esto incluye la imposibilidad de que sea objeto de intercambio por algo o por alguien, pues al ser cada persona única, valiosa, digna, carece de equivalente. «Esa es la razón por la que los seres humanos no somos una mercancía a la que se le asigna un precio, pues la mera asignación de un precio implica que puede ser sustituido por algo de equivalente valor» ${ }^{12}$. Ir en contra de ese límite - sea de manera actual o potencial- haría a dicho discurso, conducta o decisión, una actuación moralmente incorrecta, sin perjuicio de que, además, resulte políticamente inconveniente e inválida jurídicamente. Javier Mugüerza ha propuesto, en esa línea, al «límite de la condición humana» como una de las restricciones éticas de toda práctica o discurso (el otro sería la propia conciencia de cada ser humano), hasta el punto que «ninguna decisión colectiva, por mayoritaria que fuese, podría legítimamente atentar contra ella sin atentar contra la ética» ${ }^{13}$.

Frente a los intereses de la comunidad y del Estado siempre se puede oponer, en consecuencia, el simple y universal hecho de que cada ser humano es persona, por lo que no todo puede ser resuelto en términos del interés general o de la conveniencia política. Por el contrario, siempre deben considerarse las exigencias que se derivan de la dignidad. En ese sentido dice bien Rinaldo Bertolino: «Antes que el Derecho aparece la persona en su estatuto ontológico como ser moral; como "valor suprapositivo", la dignidad del hombre limita el orden del Estado. Cualidad intrínseca de la condición humana, poseída por el simple hecho de ser hombre» ${ }^{14}$.

Esto no significa caer en egoísmos o individualismos que olviden la importancia de la comunidad, ni el cuidado del resto de la naturaleza; pero sí poner de manifiesto que toda la vida social debe estar fundada y organizada a favor del desarrollo integral de la persona.

$2^{\circ}$. A diferencia de los seres humanos, los objetos no pueden plantearse fines, menos aún pueden ser fines en sí mismos. Un medio, por definición, no es un fin, sino un instrumento para alcanzar fines. Siendo cada ser humano -es decir cada persona- un fin en sí mismo, la dignidad exige que las personas no seamos instrumentalizadas, que nunca se nos trate como objetos ni como simples medios; de lo contrario se atentaría contra nuestra naturaleza humana.

12 GonzÁlez Amuchastegui, Jesús. Ob. cit., pp. 421-422.

13 Desde la perplejidad. Ensayos sobre la ética, la razón y el diálogo, Fondo de Cultura Económica, Madrid-México D. F., 1990, p. 681.

14 "La cultura moderna de los derechos y la dignidad del hombre", en Derechos y libertades, Revista del Instituto Bartolomé de las Casas, traducción de Andrea Greppi, No 7, año IV, enero de 1999, Universidad Carlos III de Madrid, Boletín Oficial del Estado, p. 136. 
30. La dignidad confirma la calidad de sujeto de la persona. Exige para ella un tratamiento que tenga en cuenta su condición de causante de los distintos órdenes normativos: de la moral, la política y el Derecho, al ser la existencia humana anterior a ellos y transcenderlos. Una exigencia que es coherente con el fin que, en sí mismo, es cada ser humano. Si cada persona es un fin en sí mismo, entonces, no debe ser tratada como objeto ni como simple medio; la única forma de no darle ese trato en el plano normativo es considerarle siempre como sujeto; esto significa reconocerle su capacidad de gozar, ejercer y cumplir, según corresponda, con derechos, deberes y otras figuras en los diferentes órdenes (la moral, la política y el Derecho). Ernst Tugendhat lo explica: cuando los seres humanos se reconocen recíprocamente como personas, se reconocen mutuamente como fines en sí, «y reconocer a alguien como fin en sí, como portador de un valor absoluto, significa no tratarlo como a un valor instrumental»; lo que supone «imponerse el precepto de no instrumentalizarle», y para no instrumentalizarle, para no tratarlo como objeto ni como simple medio, hay que «reconocerle como un sujeto de derechos» (y también de deberes, por supuesto). Habría que entender entonces el recíproco reconocimiento de nuestra calidad de personas como un reconocimiento recíproco de derechos (y deberes) ${ }^{15}$.

40. En el caso de los derechos, la dignidad exige que especialmente se reconozca a favor de las personas cierto tipo de derechos que, por ser fundamentales para la realización de las distintas dimensiones de nuestra humanidad, deben ser universalmente respetados, protegidos, garantizados y promovidos. Se trata de los llamados derechos humanos o fundamentales, que deben ser igualmente disfrutados por todas las personas a fin de que no se trate a algunos como simples medios en beneficio de otros. Es la idea básica de toda teoría y lucha por este tipo de derechos: que el ser humano no sea tratado como cosa, como objeto, sino siempre como sujeto.

Estos derechos fundamentales poseen características especiales que reflejan el eminente valor que corresponde a la persona, cumpliendo funciones al exterior del ordenamiento jurídico y al interior de este. En el primer caso la función principal de tal tipo de derechos es orientar la organización de la sociedad, y principalmente del poder y del Derecho, de acuerdo con la dignidad, para que puedan realizarse las exigencias que se derivan de esta. En el segundo caso los derechos fundamentales desempeñan a su vez dos funciones dentro del ordenamiento: por un lado, desde un punto de vista objetivo, sirven de guía para la producción, interpretación y aplicación de toda norma jurídica, de tal forma que ningún acto,

15 "La indefensión de los filósofos ante el desafío moral de nuestro tiempo", en Isegoría, Revista de Filosofía Moral y Política, traducción de Concha Roldán Panadero, No 3, abril de 1991, Madrid, p. 115. 
norma o decisión debe ser contrario a estos derechos, bajo sanción de invalidez; $y$, por otro lado, desde un punto de vista subjetivo, los derechos fundamentales traducen en normas jurídicas pretensiones morales justificadas de los individuos o de los grupos en que estos se integran, bajo la forma de derechos subjetivos propiamente dichos, de libertades, potestades e inmunidades, actuando además como límites al poder, como cauces para la participación política y social y como medio de establecer prestaciones para la satisfacción de necesidades básicas de sus titulares.

$5^{\circ}$. En cuanto a los deberes, la dignidad exige que la persona se comporte de manera coherente con el eminente valor que se le reconoce, tanto respecto de sí misma como respecto de los demás. Esto supone, por un lado, como explica José Luis Pérez-Triviño, «seguir un conjunto de mandatos y de prohibiciones, así como actuar guiados por cierto tipo de razones» para «actuar de forma congruente con nuestro status moral como fines en sí mismo, evitando cualquier tipo de acción que tenga como resultado la degradación» ${ }^{16}$. Por ejemplo, trabajar cotidianamente para procurar nuestro propio desarrollo, no incurrir en actos delictivos y conformar nuestro comportamiento con los principios morales que hayamos adoptado libremente y que nos conduzcan hacia nuestra realización integral (con respeto y consideración a los demás). Por otro lado, supone también comportarse de manera coherente con la dignidad de los demás: evitar cualquier conducta que la amenace o lesione y actuar con solidaridad y responsabilidad por el bienestar de los otros, incluyendo el cuidado de la naturaleza. Verbigracia, no actuar con desprecio, discriminación o brindando un trato hostil, cooperar con la remoción de las estructuras que mantienen la pobreza y otros contextos sociales injustos, cuidar el medio ambiente, etc.

Se justifica así el establecimiento de deberes esenciales que, al igual que los derechos fundamentales, son imprescindibles para el desarrollo integral de la persona, y para la edificación de una sociedad justa orientada a ese desarrollo. Tal tipo de sociedad no solo requiere de la vigencia real o efectiva de una serie de derechos, sino también de la realización de una serie de deberes por ser indispensables para alcanzar aquel objetivo. Se establecen deberes a cargo de las personas y de sus distintas agrupaciones (como el deber de contribuir mediante sus tributos al sostenimiento de los gastos públicos) y también a cargo del Estado, funcionarios y organizaciones estatales (como el deber de cumplir con las prestaciones para satisfacer necesidades básicas, así como los vinculados con las funciones propias del buen gobierno).

$6^{\circ}$. Al vincularse con el desarrollo integral de la persona, la dignidad exige una serie de prestaciones para favorecer ese desarrollo. Esto implica que los preceptos que se deriven

16 "La relevancia de la dignidad humana. Un comentario", en Doxa, Cuadernos de Filosofía del Derecho, N³0, 2007, p. 162. 
racionalmente de la dignidad no solo deben estar referidos a la defensa de la persona o a la prohibición de un trato indigno (prestaciones de no hacer), sino también a promover a la persona mediante prestaciones de dar o de hacer, a fin de satisfacer necesidades básicas (alimentación, salud, vivienda, trabajo, etc.) y coadyuvar a su pleno desarrollo. Sin esos preceptos, o mejor aún, sin el cumplimiento de esas exigencias, es posible que el ser humano ni siquiera pueda alcanzar, con su solo esfuerzo, los niveles mínimos de humanización para vivir realmente como persona; en cuyo caso el reconocimiento de su dignidad no sería más que un buen deseo, a lo más un acto de justicia sin fuerza real alguna. Se trata de una consecuencia con la que se puede reconocer -entre otros preceptosla calidad de derechos fundamentales de los llamados derechos económicos, sociales y culturales.

70. La dignidad ubicada como fundamento y fin último de la moral, la política y el Derecho, reclama la humanización de estos órdenes, exige que sus preceptos y estructuras respeten, defiendan, garanticen y promuevan el desarrollo de la persona en las distintas facetas de su vida.

En lo que respecta a la humanización de la moral -y por extensión, de la política y el Derecho- la dignidad exige garantizar que cada ser humano pueda elegir, diseñar y realizar su ética privada (su idea del bien, de la salvación de la virtud $y$, en general, su plan de vida, correspondiente al ámbito de la felicidad), sin interferencias ni presiones de ningún tipo, como corresponde a seres dignos; y que la sociedad esté organizada según una ética pública que contribuya a ese propósito, promoviendo que las personas puedan alcanzar su desarrollo más pleno, sin olvidar la importancia de la comunidad ni el cuidado de la naturaleza (el ámbito de la justicia).

Asimismo, si la persona es un ser que presenta distintas dimensiones que expresan su humanidad, integradas todas ellas en una unidad, si es un fin en sí mismo, que no tiene precio y que no puede ser utilizada como objeto ni como simple medio; entonces, ningún orden moral, político o jurídico puede desconocer, legítimamente, alguna de las dimensiones de la persona. No deben serles irrelevantes su naturaleza biológica, psicológica, su autonomía, racionalidad y espiritualidad, así como las demás dimensiones de su humanidad; hacerlo significaría olvidar su condición de persona, desvirtuar la totalidad de su condición humana, tratarlo como una cosa, como un objeto. Por esa misma razón, porque la persona es un fin en sí mismo, y porque sin ella no puede haber comunidad o Estado, ni ordenamiento moral, político o jurídico, ninguno de estos órdenes puede establecer legítimamente actos o normas que contravengan su condición. Antes bien, deben orientarse hacia su respeto, protección, garantía y promoción; hacia el desarrollo integral de la persona: hacer todo lo posible para que cada persona esté en condiciones de realizar -con su esfuerzo, pero con el apoyo de los demás- todas las dimensiones de su humanidad. 
Agustín Basave, en cuanto al orden jurídico se refiere, sostiene: «La dimensión jurídica del hombre no puede desconocer ni la estructura permanente y general del ser humano -elemento nuclear, ni el autoproyecto cambiante en situación histórica. Las leyes ontológicas del ser del hombre no son -no podrían ser- irrelevantes para el orden jurídico». Si se tiene en cuenta que «la esfera culturalantropológica con sus cambiantes proyectos se refleja en las instituciones sociales», entonces «la contemplación jurídica debe tomar como base una imagen ideo-existencial del hombre. El deberser-comportarse de una manera y no de otra- descansa sobre el ser del hombre -cuerpo, psique, espíritu-». Dicho en otros términos, «una antropología integral está en la base de una antropología jurídica. La estructura estratificada del hombre -estrato biológico, estrato psíquico, estrato espiritual- con su legalidad propia no puede ser desconocida por el Derecho»17.

$8^{\circ}$. Al ubicarse como fundamento y fin último de la moral, la política y el Derecho, la dignidad sirve también como criterio para evaluar la corrección, legitimidad y justicia en esos órdenes, para orientar y delimitar la producción, interpretación y aplicación de sus preceptos y actuaciones. Cuando es incorporada al ordenamiento jurídico, especialmente a su norma de mayor jerarquía, sirve además como máximo criterio de validez jurídica, a fin de que ninguna norma - actuación sea contraria a la persona sino, por el contrario, favorezca su realización más plena. Así, refiriéndose al caso español, Pedro Serna explica que el artículo 10.1 de la Constitución, al atribuir a la dignidad «unos derechos inviolables que le son inherentes» y calificarla como el «fundamento del orden político y de la paz social», no solo funda con ella los derechos sino también el completo orden jurídico; se presenta, por tanto, como «criterio hermenéutico que limita, en cuanto a su validez, posibles interpretaciones de otros principios de la Constitución que pudiesen tener efectos contrarios al respeto a la persona», como ocurriría con «una concepción del principio de soberanía que condujese a considerar, en clave puramente formalista, el principio de legitimidad democrática que consagra la Carta magna»18.

90. En el caso de los derechos fundamentales, por ejemplo, la dignidad sirve como referente para guiar su desarrollo normativo y delimitar tanto su contenido como su ejercicio. Sirve para establecer qué exigencias pueden formar parte del contenido de esos derechos por ser favorables al desarrollo integral de la persona, y qué exigencias no pueden serlo por deshumanizarla o ser contrarias a la

\footnotetext{
17 "Hacia una antropología jurídica integral: la dimensión jurídica del hombre como fundamento de la Filosofía del Derecho", en Persona y Derecho, Revista de Fundamentación de las Instituciones Jurídicas y de Derechos Humanos, No 7, 1980, Universidad de Navarra, Pamplona, p. 241.

18 "La dignidad de la persona como principio del derecho público", en Derechos y libertades, Revista del Instituto Bartolomé de las Casas, No 4, año II, enero-junio de 1995, Universidad Carlos III de Madrid, Boletín Oficial del Estado, p. 297.
} 
dignidad que le corresponde. En armonía con ello el Tribunal Constitucional español ha señalado que «la regla del artículo $10.1 \mathrm{CE}$, proyectada sobre los derechos individuales, implica que la dignidad ha de permanecer inalterada cualquiera que sea la situación en que la persona se encuentre»; de esa manera constituye «un minimun invulnerable que todo estatuto jurídico debe asegurar, de modo que las limitaciones que se impongan en el disfrute de derechos individuales no conlleven un menosprecio para la estima que, en cuanto ser humano, merece la persona»19.

Por esa misma razón, la dignidad sirve como criterio para determinar cómo se deben ejercer los derechos para ser compatibles con ella y qué actuaciones no pueden ser protegidas por el ámbito de validez del derecho por resultar un comportamiento indigno. Además, sirve como criterio para determinar lo que puede ser considerado como derecho fundamental o perteneciente a tal tipo de derechos. No deberá serlo aquella pretensión que deshumanice al ser humano, que vaya en contra de alguna de sus dimensiones o que afecte su inviolabilidad; por el contrario, demandará tener tal carácter aquella pretensión cuya satisfacción contribuya a su desarrollo, al respeto, protección, garantía y promoción de su dignidad. Es también la postura de Robert Spaemann, para quien «el concepto mismo de dignidad humana es -como el de libertad- un concepto trascendental. Este concepto no indica de modo inmediato un derecho humano específico, sino que contiene la fundamentación de lo que puede ser considerado como derecho humano en general» 20 .

\section{2.- LA DIGNIDAD Y EL DINAMISMO DE LA LIBERTAD: DE LA LIBERTAD DE ELECCIÓN A LA LIBERTAD MORAL}

La dignidad encuentra conexión con la libertad, la autonomía y la moral. Desarrollando estas ideas, podemos decir con Gregorio Peces-Barba que, desde un punto de vista moral, la libertad tiene dos momentos, dos maneras de expresarse comunicadas entre sí: la libertad de elección y la libertad moral ${ }^{21}$.

La libertad de elección es una libertad inicial, básica, referida única y exclusivamente a la capacidad íntima de elegir. No está referida todavía a los condicionamientos y factores que influyen en la posibilidad de elección, ni a las necesidades humanas que deben ser satisfechas para que el ser humano pueda estar en condiciones reales e iguales de elegir. Es un rasgo humano que emerge, en última instancia, a partir de una serie de cualidades físicas, biológicas y

19 STC 57/94, de 28 de febrero de 1994, publicada en Boletín de Jurisprudencia Constitucional, N 155, Cortes Generales de España, Madrid, 1994, p. 227.

20 "Sobre el concepto de dignidad humana", en Persona y Derecho, Revista de Fundamentación de las Instituciones Jurídicas y de Derechos Humanos, traducción de Daniel Innerarity, No 19, 1988, Universidad de Navarra, Pamplona, p. 15.

${ }^{21}$ Cfr. su obra: Introducción a la filosofía del derecho, Serie de Derecho, Debate, Madrid, 1983, p. 60. 
sicológicas, orientando su acción y reflexión. Significa que el ser humano - de manera gradual a las distintas etapas de su desarrollosiempre puede elegir. A pesar de sus condicionamientos históricos, económicos, culturales, etc., por más difíciles que sean sus circunstancias, el ser humano tiene la capacidad -actual o potencialde optar por uno u otro camino, decidir entre lo bueno o lo malo, lo justo o lo injusto, aceptar una proposición o negarse a ella, aun cuando tenga que afrontar las consecuencias de sus propias decisiones. De esta manera, el ser humano tiene la posibilidad de autodeterminarse racionalmente, de obrar moralmente, al margen de sus necesidades y de aquellos factores de los que pueda depender coyunturalmente. No está garantizado que elijamos bien, también podemos equivocarnos, pero ese es un riesgo que debemos correr como personas libres que escogen su propio camino.

La libertad de elección es importante porque a través de ella el ser humano toma decisiones vinculadas con su vida personal, sus relaciones con los demás $y$, en general, con las diversas situaciones de la vida social e histórica. Sin ella no puede haber vida social, ni historia ni cultura; simplemente no existirían importantes aspectos distintivos de la humanidad ${ }^{22}$. Es importante también porque es un presupuesto de la moral: sin ella no podríamos elegir entre las diversas posibilidades y no podría hablarse en términos éticos. Por esa razón, la libertad de elección es el punto de partida de la empresa de ser persona, requisito imprescindible para alcanzar el desarrollo humano. A partir de ella, el hombre y la mujer eligen y dirigen sus actuaciones para alcanzar la libertad moral 23.

La libertad moral, llamada también libertad autonomía o autonomía moral, es la libertad final: el estado en que el ser humano logra el máximo grado de realización de todas las dimensiones de su ser, el desarrollo integral de su condición de persona. Es la situación que el ser humano ha alcanzado como resultado de haber elegido bien, de haber elegido -en cada caso- una opción compatible con todas las dimensiones de su humanidad.

A partir de la libertad de elección, que es un punto de partida, cada persona debe construir su libertad moral, que es el punto de llegada tras toda una vida. Una empresa que exige de la persona un esfuerzo constante -con sus errores y tropiezos, pero también con su decisión y fortaleza- para ser dueña de sí misma, gobernante de su propia vida, para alcanzar la plenitud de su humanidad, haciendo uso correcto de su libertad de elección, desprendiéndose y superando los obstáculos y condicionamientos que se encuentran en su propia vida,

\footnotetext{
${ }^{22}$ Cfr.: PeCES-BARBA, Gregorio. Ibíd., p. 57.

23 Véase: PeCES-BARBA, Gregorio. Curso de Derechos Fundamentales. Teoría general (1995), con la colaboración de Rafael de Asís, Rafael Fernández Liesa y Ángel Llamas Gascón, Universidad Carlos III de Madrid, Boletín Oficial del Estado, Madrid, reimpresión de 1999, p. 229.
} 
así como en la vida social, que impiden o dificultan su autenticidad y el desarrollo de todas las dimensiones de su ser ${ }^{24}$.

Para alcanzar la libertad moral, y como parte de ese esfuerzo, el ser humano debe construir su propio plan de vida, buscar el bien, la felicidad, la virtud, y trabajar cotidianamente para realizarla a fin de desarrollarse integralmente. Al mismo tiempo, debe buscar la justicia, no ser egoísta, ni indiferente con la suerte de los demás; sino, por el contrario, debe cooperar con el bienestar de los otros, en una mutua responsabilidad y solidaridad que tenga como objetivo final la humanización de todos y cada uno de los miembros de la familia humana. Solamente así se puede trabajar seria y cabalmente para alcanzar el desarrollo integral, pues este es imposible alcanzarlo en solitario. Debe además cuidar el resto de la naturaleza porque no se puede alcanzar un desarrollo humano, real y vivificador, prescindiendo de ella.

Debido a su alto nivel de exigencia, la libertad moral es una meta, un ideal a alcanzar, quizá la utopía de la condición humana, un proyecto difícil pero posible. Mientras la libertad de elección es un rasgo que ya le viene dado a cada sujeto, la libertad moral es un rasgo que debe construirse día a día con la interacción y la cooperación social. «A través de la acción siempre difícil y condicionada, muchas veces traicionada y desoída de la libertad de elección, el hombre construye su vida hacia la libertad de autonomía, la libertad moral, es decir a través de la sucesiva superación de obstáculos y condicionamientos que se encuentran en la propia vida de cada uno y en la vida social y que dificultan la autenticidad» 25 .

Estos dos sentidos de libertad se comunican entre sí, y solo pueden ser cabalmente entendidos si se los estudia de manera vinculada. Ambas integran lo que con buen criterio Peces-Barba denomina el dinamismo de la libertad, que va desde la libertad de elección hacia la libertad moral ${ }^{26}$. Una dinámica relación donde ambos extremos se necesitan y condicionan recíprocamente. Así, «la libertad de elección es la base de la libertad moral», pues solo puede hablarse de libertad moral porque existe libertad de elección; y la libertad de elección solo es coherente cuando actúa para realizar los fines que permiten alcanzar la libertad moral. Ambas son necesarias y prescindir de alguna perjudica o destruye a la otra. Por eso insistimos: «la libertad de elección es condición de la libertad moral, y la libertad moral [es la] meta de la libertad de elección» 27.

Ese dinamismo nos permite apreciar que la libertad, en su sentido más profundo, no es la simple posibilidad de elección, la capacidad de decidir lo que se quiera. La libertad, la verdadera

\footnotetext{
24 Véase: PeCES-BARBA, Gregorio. Ibíd., p. 230.

25 PeCES-BARBA, Gregorio. Introducción a la Filosofía del Derecho, ob. cit., p. 60.

26 Véase: Ibíd. También del mismo autor: Curso de Derechos Fundamentales, ob. cit., pp. 231-234.

27 PeCES-BARBA, Gregorio. Ibíd., p. 231.
} 
libertad, es elegir el bien, rechazar el mal, es elegir lo justo, rechazando lo injusto. Está orientada al desarrollo integral de la persona, sin prescindir de los demás ni descuidar la naturaleza. No podría invocarse la libertad -por poner un ejemplo- para elegir en contra de la libertad misma (como ocurriría si se eligiera ser esclavo), ni para lesionar cualquier otra dimensión de la persona (como ocurriría si se mutilase arbitrariamente el propio cuerpo). Además de ser una contradicción en sus términos, tal elección pervertiría la libertad al atentar contra la dignidad de quien elige.

Por lo tanto, ni la libertad de elección -por su orientación- ni la libertad moral -por definición- pueden ser contrarias a la dignidad. Ni una ni otra deben dar lugar a decisiones que menoscaben alguna de las dimensiones del ser humano -sea del propio individuo que toma la decisión o de los demás- porque eso significaría actuar en contra de la condición humana. Significaría tratar a la persona no como fin, sino como un objeto, como un simple medio. En ese caso, estaríamos ante un comportamiento inmoral por indigno, sin perjuicio de que además resulte inconveniente desde el punto de vista político e inválido desde el enfoque jurídico. Lo explican Melendo y MillánPuelles: «[L]a dignidad humana va mucho más allá del simple arbitrio, entendido como mera capacidad de optar», pues «la innegable excelsitud del sujeto humano se infiere sin posibilidad de equívocos de su intrínseco poder de autodeterminación solo cuando este se advierte con perspicacia en la totalidad de sus dimensiones». Dicho con palabras más concretas, «la libertad es signo privilegiado de la grandeza humana no solo porque gracias a ella el hombre puede conducirse por sí mismo, sino también y de manera indisoluble, porque por sí mismo puede encaminarse hacia el propio bien o plenitud terminales» 28 .

Es también la posición de Tomás Prieto, quien advierte que considerar a la libertad de elección como una completa e incondicionada libertad de la persona para autodeterminarse -con vistas a su propio desarrollo-, según lo quiera entender cada cual, sin límite alguno, «no solo implicaría proscribir cualquier consideración de la dignidad como valor absoluto de contenido suficientemente objetivo -con lo que la precisión de su contenido es remitida a la conciencia de cada uno-», sino que además supondría «otorgar una relevancia aquí sí absoluta al consentimiento de la persona (sujeto pasivo o "víctima", o incluso sujeto activo) para considerar o no como indigno un comportamiento dado -de modo que, aunque razonablemente sea considerado como inicuo, pueda no serlo en la medida que el sujeto que lo padece lo consienta-». Una constatación por la que concluye: «[...] esta identificación entre dignidad y pura autonomía, que desliga a aquélla de parámetros racionales-naturales, equivale, en el fondo, a convertir la dignidad humana en una "palabra vacía" [...] y representa una amenaza para el hombre, absolutamente

${ }^{28}$ Dignidad: ¿una palabra vacía?, Eunsa, Pamplona, 1996, pp. 61-62. 
manifiesta en la civilización moderna, tan proclive a vaciar aquella dignidad en la medida en que la remite al dictamen de cada cual» 29.

\section{3.- EL EQUILIBRIO ENTRE LOS PRINCIPIOS DE AUTONOMÍA Y UNIVERSALIDAD}

Si de manera actual o potencial el ser humano es libre para autodeterminarse racionalmente en el plano moral, independientemente de las causas externas que incidan sobre él (libertad de elección); entonces, puede crear o asumir libremente su propio plan de vida, sus propias normas para regir su destino y alcanzar su emancipación o desarrollo integral (autonomía moral) ${ }^{30}$. Al ser potencialmente capaz de tal actuación el ser humano es un ser de fines, un sujeto que no tiene precio, que «existe como un fin en sí mismo, no simplemente como un medio para ser utilizado discrecionalmente por esta o aquella voluntad»31. Por esa razón, como nos lo recuerda Immanuel Kant, en todas sus acciones, «tanto en las acciones orientadas hacia sí mismo como en las dirigidas hacia otros seres racionales el hombre ha de ser considerado siempre al mismo tiempo como un fin», nunca como simple medio, ni mucho menos como objeto, porque tiene dignidad ${ }^{32}$. Para asegurar ese propósito, las acciones o decisiones que se adopten deben considerar siempre la igual dignidad que corresponde a todos los miembros de la familia humana. No podría defenderse la dignidad de uno y negársela a los demás. Por lo tanto, para que las acciones o decisiones sean moralmente válidas no solo deben ser producto de la libertad de elección y del uso autónomo de la razón, sino también ser imparciales, no egoístas ni utilitaristas, sino susceptibles de ser elevadas a ley general.

Son exigencias propias de los principios de autonomía y universalidad, que se derivan racionalmente de la dignidad humana y se encuentran orientados por ella. Dos principios éticos procedimentales -de raigambre humanista y raíz kantiana- pues, a diferencia de los materiales, no nos dicen qué es lo moralmente correcto en cada caso; tan solo nos indican las pautas que se deben seguir para determinarlo. En otras palabras, estos principios nos proporcionan los criterios a seguir para asegurar que la libertad de elección sea coherente con la libertad moral o, lo que es lo mismo, para que esté orientada hacia la plena realización de la dignidad humana. Además, permiten fundamentar la validez moral de los enunciados y juicios morales, generar normas morales válidas y

${ }^{29}$ La dignidad de la persona: núcleo de la moralidad y el orden públicos, límite al ejercicio de las libertades públicas, Monografías, Civitas, Madrid, 2005, pp. 203204.

30 Véase: KANT, Immanuel. Ob. cit., pp. 140-143.

${ }^{31}$ KaNT, Immanuel. Ibíd., p. 114.

32 Ibíd. 
evaluar las existentes, así como resolver los problemas morales concretos o los conflictos de acción que se puedan presentar.

Según el principio de autonomía, toda conducta, criterio, norma o decisión que aspire a ser considerada como moral, no debe ser impuesta. El ser humano debe tener libertad para autodeterminarse racionalmente, de lo contrario se vulneraría su dignidad. Lejos de ser tratado como un sujeto, sería tratado como un simple objeto. Por esa razón, en cualquiera de sus clasificaciones o sentidos, la moral requiere de la libre elección de la persona. El papel que juega en ella el individuo es imprescindible, e irremplazable el lugar que ocupa su conciencia moral para elegir libremente y en forma responsable. Incluso la moral social no puede ser impuesta. A la moral social le sigue el examen, la aceptación o el rechazo individual. La moral debe originarse fundamentalmente en la conciencia moral del individuo o no será moral. En esa línea, explica Eusebio Fernández: «La conciencia moral de cada uno obra con total libertad y autonomía, tanto si decide observar la moral vigente en su sociedad como si decide poner en cuestión o desdeñar las normas y valores morales establecidos». Quien acepta, observa, cuestiona o rechaza determinados modelos de conducta moral es el ser humano en su más estricta individualidad $y$, «como tal, no puede transferir la responsabilidad de su opción a nadie» 33 .

El principio de universalidad exige que toda conducta, criterio, norma o decisión que pretenda ser considerada como moral, no sea el producto de un subjetivismo ético, de un simple capricho o arbitrariedad, sino una elección adoptada por la razón y susceptible de ser elevada a ley general; es decir, que todos puedan quererla igualmente porque satisface intereses universalizables. Immanuel Kant nos lo recuerda así: «[O]bra solo según aquella máxima por la cual puedas querer que al mismo tiempo se convierta en una ley universal»; o, dicho de otra forma, «obra como si la máxima de tu acción pudiera convertirse por tu voluntad en una ley universal de la naturaleza»34. Para lograr ese propósito, las normas morales deben ser determinadas con imparcialidad de modo tal que lo prescrito logre un reconocimiento universal. $Y$ como dice Ernst Tugendhat, la imparcialidad supone tomar una decisión «que tenga igualmente en cuenta a todos», requiere que nos pongamos mentalmente «-de forma hipotética- en [el] lugar de todos los demás» 35 . Tal exigencia no desconoce los cambios históricos ni la influencia de la cultura en la determinación de lo que es moralmente correcto; por el contrario, se encuentra abierta a ellos permitiendo que la reflexión racional perfeccione las prescripciones morales $y$ se postulen nuevas

\footnotetext{
33 "Sobre la ética y su justificación", en Estudios de Ética jurídica, Serie de Derecho, Debate, Madrid, 1990, p. 102.

34 Ob. cit., p. 104.

35 Problemas de ética, Crítica, Barcelona, 1988, pp. 114 y 134.
} 
pretensiones, siempre y cuando, claro está, sean también universalizables y coadyuven al desarrollo integral de la persona.

Con este planteamiento se excluyen las concepciones éticas egoístas y utilitaristas. No sería posible una moral calculada, sea a favor de la mayoría o del individuo que la esgrime, sino que los principios morales deben estar siempre presentes, aunque no produzcan beneficios en un caso concreto. Tampoco sería moral una elección o un planteamiento dirigido a obstaculizar o impedir el desarrollo integral de la persona o que la someta a una situación de indignidad. Se pretende evitar así que unos se beneficien indebidamente a costa de los demás $y$, en general, garantizar que las normas o elecciones sean compatibles con la igual dignidad que corresponde a todas las personas. La asunción de este principio hace que el punto de vista moral sea una operación de universalización de las máximas e intereses controvertidos en el que las partes valoran imparcialmente los intereses de todos, trascendiendo el contexto social o cultural en el que se encuentren y las circunstancias contingentes que puedan existir, a fin de adoptar una decisión moralmente válida susceptible de ser aceptada por todos ${ }^{36}$. Un camino epistemológico que se aparta de los particularismos y relativismos, pues, partiendo de la igual dignidad de las personas, las decisiones o normas morales: o son universales o no son morales (serán inmorales o amorales, según sea el caso, por ejemplo, dependiendo de si vulneran o no alguna dimensión de la naturaleza humana). Se diferencia, además, del punto de vista político y jurídico porque las normas o decisiones, para ser válidas en estos órdenes, no necesitan cumplir con las exigencias de la universalidad, sino con los criterios de conveniencia y juridicidad, respectivamente.

Resulta importante insistir en que los principios de autonomía y universalidad, tal como se encuentran definidos -inclusive en el sistema moral kantiano- se encuentran orientados siempre por la dignidad humana. Esta se presenta racionalmente como su fundamento y como la meta última que persiguen, como el principal referente que delimita sus exigencias y permite establecer su significado práctico. Ambos principios concurren en una situación de equilibrio, orientados siempre al desarrollo integral de la persona. Por eso se debe «descartar tanto las éticas que se centran en el valor exclusivo del principio de universalización como aquellas que se basan exclusivamente en el principio de autonomía» 37.

Las éticas que prescinden del principio de autonomía son aquellas que pretenden una aceptación casi automática de sus postulados, por parte de las personas a las que se dirigen. Son éticas

36 Véase: HABERMAS, Jürgen. "Aclaraciones a la ética del discurso" (1991), en sus: Aclaraciones a la ética del discurso, Colección: Estructuras y Procesos, traducción de José Mardomingo, Trotta, Madrid, 2000, pp. 132-133.

37 Peces-Barba, Gregorio. Ética, poder y derecho. Reflexiones ante el fin de siglo, Cuadernos y Debates, No 54, Centro de Estudios Constitucionales, Madrid, 1995, p. 60. 
autoritarias que pretenden imponer sus contenidos y que diseñan los planes de vida de las personas al margen de su voluntad. En ellas el dinamismo de la libertad desaparece pues el individuo ya no puede elegir: se prescinde de su libertad, de su autonomía como aceptación responsable de su moralidad. Son éticas incompatibles con cualquier otra cosa que no consideren verdaderas, rechazan el pluralismo y son propias de sociedades cerradas. Suelen ser éticas fundamentalistas, integristas y totalitarias.

Las éticas que prescinden del principio de universalidad parten por considerar que es imposible que se puedan ofrecer propuestas morales a ser consideradas o aceptadas por todos. Son éticas relativistas que se basan en la subjetividad o en los particularismos. Suelen complacerse en el aislamiento, tanto en la sociedad como en la política, favoreciendo el retiro hacia el ámbito grupal o a la privacidad sin abrirse al encuentro con los demás.

La idea de persona y dignidad humana rechaza esos dos reduccionismos, al integrar tanto el principio de autonomía como el de universalidad en una relación de complementariedad, orientados siempre por la dignidad humana.

\section{4.- UN PUNTO DE PARTIDA Y UN PUNTO DE LLEGADA}

La reflexión sobre la persona y la dignidad humana no solo debe atender a su significado, a los fundamentos que la justifican y a los preceptos o consecuencias normativas que racionalmente se derivan de ella, sino también a las condiciones y actuaciones que son necesarias para que las personas se realicen plenamente en la realidad. Debe ir acompañada de esfuerzos cotidianos y sostenidos, iluminados por la verdad y guiados por la razón. En esa tarea la sociedad y el Estado tienen un papel importante que cumplir, a través de la correcta ordenación de la sociedad, de la función promocional del Derecho, de la eliminación de las barreras y del cumplimiento de prestaciones positivas y negativas (de dar, hacer y no hacer), etc.; pero también la persona, individualmente considerada, tiene que poner los medios adecuados para plasmarla. Una serie de exigencias y requisitos a cuya satisfacción deben orientarse los distintos ámbitos de la vida social, bajo la constatación de que la dignidad no solo es un atributo sino también un proyecto que día a día debe realizarse y conquistarse.

En ese esfuerzo la dignidad se presenta como un punto de partida, pero también como un punto de llegada. Es un punto de partida porque de ella podemos derivar racionalmente las prescripciones que deben ser cumplidas por los particulares, la sociedad y el Estado para construir una sociedad justa orientada al pleno desarrollo de las personas. Pero la dignidad es también un punto de llegada: no solamente una cualidad de la persona que genera preceptos -con mediación de la razón- sino también un proyecto que debe realizarse y conquistarse; un deber ser que se 
realiza en el dinamismo de la vida, siempre condicionado históricamente y limitado temporalmente. En otros términos, la dignidad es también una meta, un proyecto de realización humana, que quizá no llegue a alcanzarse plenamente en la realidad -por los condicionamientos históricos existentes- pero a cuya consecución jamás debe renunciarse. Un proyecto difícil, pero posible, al que debemos comprometernos todos: el individuo, la sociedad, el Estado; porque su cabal consecución no puede alcanzarse en solitario, requiere de esfuerzos serios, recíprocos y apoyos constantes.

Este enfoque no pretende relativizar el contenido de la dignidad, mucho menos restarle fuerza o justificación a las prescripciones que se deriven de ella. Tan solo poner de manifiesto que estas no se satisfacen de una vez y para siempre; que el pleno desarrollo de la persona es un horizonte utópico, aunque posible de alcanzar; que la complejidad de la condición humana y los cambios de la vida social generan nuevas exigencias vinculadas con la dignidad que deben ser igualmente satisfechas; y que su cabal realización se encuentra muchas veces condicionada a una serie de factores, como la escasez y la pobreza. No implica, en lo absoluto, que cualquier conducta o decisión sea compatible con la dignidad, ni afecta el deber ser de sus prescripciones. Por tanto, partiendo de este deber ser (dignidad como punto de partida), corresponde al individuo, al Estado y a los diversos ámbitos de la sociedad cumplir con realizar cotidianamente esas exigencias para intentar alcanzar ese horizonte, aunque tal esfuerzo se encuentre condicionado históricamente (dignidad como punto de llegada).

Entre la dignidad como punto de partida y la dignidad como punto de llegada se ubican los preceptos morales, políticos y jurídicos que, al compartir ese mismo origen y perseguir esa misma meta, deben estar orientados a respetar, garantizar, defender y promover a la persona y su pleno desarrollo. De esta manera se contará con los materiales necesarios para construir y fortalecer una sociedad justa orientada al desarrollo integral de la persona. Algunos de esos materiales, que son requisitos imprescindibles para alcanzar ese propósito, son los siguientes ${ }^{38}$ :

$1^{\circ}$. El reconocimiento recíproco de la igual dignidad de todos los seres humanos.

20. La defensa de la vida.

$3^{\circ}$. El rechazo a la violencia y la lucha por la paz.

40. La libertad, la igualdad, la seguridad y la solidaridad.

50. La actuación promocional del poder y del Derecho.

38 Cfr. Peces-Barba, Gregorio. La España civil, Voces Libres, Galaxia Gutenberg, Círculo de Lectores, Barcelona, 2005, pp. 162-171; y "Reflexiones sobre la democracia en la sociedad", en La democracia a debate, et. al.: Rafael de Asís Roig; eds.: José Antonio López García, José Alberto del Real Alcalá, Ramón Ruiz, Dykinson, Madrid, 2002, pp. 51-52. 
$6^{\circ}$. La protección de la conciencia individual y de la capacidad de cada uno de elegir y realizar su plan de vida.

$7^{\circ}$. La existencia de un espacio público donde las diferentes propuestas puedan expresarse libremente, con todo lo que supone: pluralismo, libertad ideológica, de conciencia, laicidad, etc.

$8^{\circ}$. Pluralismo de diversas ofertas políticas razonables que se superponen y que no son incompatibles. Estas son aquellas que, si bien se distinguen unas de otras por los valores que asumen, presentan una cierta estabilidad, no impiden la expresión de las otras $y$, aunque creen en su verdad, no desean imponerla ni llegan a considerarla como la única respuesta correcta a los problemas prácticos que se puedan presentar. Por eso una sociedad justa requiere de la tolerancia, excluye el fundamentalismo y las éticas autoritarias.

$9^{\circ}$. El reconocimiento de la ética del disenso, que implica no aceptar la ética de la mayoría, aunque siempre dentro de un marco de respeto, de tolerancia y del reconocimiento recíproco de la dignidad del otro. El disenso muchas veces puede generar nuevos consensos y descubrir nuevas dimensiones de moralidad. Además, garantiza que las personas no actúen en contra de su ética privada y contribuye a perfeccionar el orden moral vigente. Por esa razón se debe evitar el establecimiento de obligaciones jurídicas generales que interfieran en la moral de las personas y, si tal situación se produce, establecer la exención del cumplimiento de la obligación a través de la objeción de conciencia para aquellos casos puntuales que estén razonablemente justificados.

$10^{\circ}$. El reconocimiento y garantía de los derechos fundamentales, de los deberes esenciales, así como de los valores y demás principios derivados de la dignidad humana. En el caso de los derechos, tanto de los denominados individuales, civiles y políticos, como de los llamados económicos, sociales y culturales, entre otros.

$11^{\circ}$. La asunción de una democracia integral que comprenda la democracia formal, referida a la legitimidad de origen y de ejercicio del poder político, así como la democracia material, que supone la asunción de una serie de valores, principios y derechos que son incorporados al contenido de justicia del Derecho.

$12^{\circ}$. La obligación prima facie de respetar el juego limpio y la lealtad al sistema. Esto implica la obligación de seguir las normas que uno ha aceptado por consenso y de actuar de acuerdo con ellas cuando llega la hora de hacerlo, a menos que surjan nuevas consideraciones que justifiquen razonablemente apartarse de ellas. No se trata de una lealtad ciega, pusilánime, tampoco de una lealtad a autoridades o proyectos ilegítimos. Se trata de una lealtad crítica, deliberativa y defensora de los valores y postulados que hacen posible una sociedad justa, una lealtad que no abandone las reglas de juego ante las dificultades, sino que luche por su mejora, virtualidad y realización. 
13․ El sentido de bien común, que entre otras cosas exige imparcialidad de la Administración en su gestión para no favorecer a grupos sectoriales o de presión, sino actuar en beneficio de todos.

$14^{\circ}$. La importancia de los partidos políticos y demás instituciones que garantizan el equilibrio del juego democrático, como el Congreso y el Poder Judicial, entre otros.

$15^{\circ}$. Los mecanismos de control del poder; tanto sociales, políticos como jurídicos.

En la ejecución de este proyecto resulta valioso que todos participemos, desde la situación en la que nos encontremos o nos toque vivir, en una acción solidaria que tenga como punto de partida el reconocimiento de la dignidad del otro y la consideración de sus problemas cono no ajenos, sino susceptibles de solución con intervención de los poderes públicos y de las demás personas; y como objetivo político la construcción de una sociedad justa en la que todos se consideren como miembros de la misma y resuelvan dentro de ella sus necesidades básicas, sin saltos cualitativos entre las personas, a fin de que todos podamos alcanzar nuestro desarrollo integral ${ }^{39}$. Ese objetivo político supone ayudar especialmente a las personas que se encuentran en la situación más débil, son víctimas de contextos injustos o se encuentran en una circunstancia menos favorecida. También contribuir a la creación de cauces de comunicación en la sociedad que favorezcan el diálogo entre las personas para encontrar criterios que superen el individualismo y satisfagan el bien común, además de reconocer derechos y distribuir deberes, no solo a cargo de los poderes públicos, sino también de los particulares, para favorecer el pleno desarrollo de todas las personas y el cuidado de la naturaleza. En ello se juega nuestro destino, el de nuestros hijos y el de las generaciones futuras.

39 Cfr.: PeCES-BARBA, Gregorio. Curso de Derechos Fundamentales, ob. cit., pp. 279282. 